\title{
Control of Enterotoxin Gene Expression in Bacillus cereus F4430/73 Involves the Redox-Sensitive ResDE Signal Transduction System
}

\author{
Catherine Duport,* Assia Zigha, Eric Rosenfeld, $\dagger$ and Philippe Schmitt \\ Université d'Avignon, UMR A408, Sécurité et Qualité des Produits d'Origine Végétale, INRA, Avignon F-84914, France
}

Received 17 May 2006/Accepted 5 July 2006

\begin{abstract}
In contrast to Bacillus subtilis, the role of the two-component regulatory system ResDE has not yet been investigated in the facultative anaerobe Bacillus cereus. We examined the role of ResDE in the food-borne pathogen $B$. cereus $\mathbf{F 4 4 3 0 / 7 3}$ by constructing res $D E$ and $r e s E$ mutants. Growth performances, glucose metabolism, and expression of hemolysin $\mathrm{BL}(\mathrm{Hbl})$ and nonhemolytic enterotoxin (Nhe) were analyzed in the three strains under distinct oxygenation and extracellular oxidoreduction potential (ORP) conditions. We show that growth and glucose metabolism were only moderately perturbed in both res $D E$ and res $E$ mutants under aerobiosis, microaerobiosis, and anaerobiosis generated under $\mathrm{N}_{2}$ atmosphere (initial $\mathrm{ORP}=+45 \mathrm{mV}$ ). The major effects of $r e s D E$ and $r e s E$ mutations were observed under low-ORP anaerobic conditions generated under hydrogen atmosphere (iORP $=-148 \mathrm{mV}$ ). These conditions normally favor enterotoxin production in the wild type. The res $E$ mutation was more deleterious to the cells than the res $D E$ mutation, causing growth limitation and strong deregulation of key catabolic genes. More importantly, the res $E$ mutation abolished the production of enterotoxins under all of the conditions examined. The res $D E$ mutation only decreased enterotoxin expression under anaerobiosis, with a more pronounced effect under low-ORP conditions. Thus, the ResDE system was found to exert major control on both fermentative growth and enterotoxin expression, and it is concluded that the ResDE system of $B$. cereus should be considered an anaerobic redox regulator. The data presented also provide evidence that the ResDE-dependent regulation of enterotoxins might function at least partially independently of the pleiotropic virulence gene regulator PlcR.
\end{abstract}

The facultative anaerobic, spore-forming Bacillus cereus has gained notoriety as an opportunistic human pathogen capable of causing a wide variety of diseases ranging from periodontitis, endophthalmitis, and meningitis in immunocompromised patients to the more frequent gastrointestinal infections (24, 44). B. cereus is associated with two types of gastrointestinal infection, both causing diarrhea and vomiting after the ingestion of a contaminated food. Recent evidence suggests that $B$. cereus cells are primarily ingested as spores and that the spores are able to adhere to the mucosal epithelium of the small intestine, where they can then germinate (52). The resulting vegetative cells produce three enterotoxins responsible for diarrheal symptoms $(2,8,18)$. These enterotoxins are hemolysin BL (Hbl) (4), nonhemolytic enterotoxin (Nhe) (27), and the single cytotoxin protein Cyt $\mathrm{K}(11,28)$. Hbl is composed of three proteins L2, L1, and B encoded by genes clustered into an operon with the transcriptional order $h b l C, h b l D$, and $h b l A$ (42). All three components need to be excreted to induce biological effects, which include enterotoxic activity and hemolytic and dermonecrotic activities $(5,6)$. Nhe is also a threecomponent enterotoxin. It was first isolated from an Hbl-negative strain of $B$. cereus involved in a large food-poisoning outbreak (27). The three components NheA, NheB, and NheC

\footnotetext{
* Corresponding author. Mailing address: Université d'Avignon, UMR A408, Sécurité et Qualité des Produits d'Origine Végétale, INRA, Avignon F-84914, France. Phone: 334327225 07. Fax: 33432 7224 92. E-mail: catherine.duport@univ-avignon.fr.

$\dagger$ Present address: Laboratoire de Biotechnologies et Chimie Bioorganique FRE 2766, CNRS, Bâtiment Marie-Curie, Pôle Sciences et Technologies, Université de La Rochelle, Avenue Michel Crépeau, 17042 La Rochelle Cedex 1, France.
}

differ from those of $\mathrm{Hbl}$, and Nhe has no detectable hemolytic activity $(15,26,27)$. The nhe $A B C$ gene cluster is also transcribed as an operon (26). To date, the only transcriptional activator of enterotoxin genes identified in B. cereus is the pleiotropic phospholipase regulator $\operatorname{PlcR}(1,13,37,46)$.

Previously, we showed that anaerobic B. cereus cells produced more enterotoxins than aerobic cells in $\mathrm{pH}$-controlled batch culture $(\mathrm{pH}=7.2)$, especially since the oxidoreduction potential (ORP) of the medium was low $(10,55)$. A major finding was that change in enterotoxin expression was linked to changes in primary metabolism, such as anabolism and catabolism. Aerobic and anaerobic catabolisms in B. cereus require different pathways (Fig. 1). In the presence of oxygen, reducing equivalents generated by glycolysis and the Krebs cycle are reoxidized by the respiratory chain, resulting in the buildup of a proton motive force and the subsequent synthesis of ATP by the ATP synthase. Although it has not yet been thoroughly studied, the aerobic respiratory chain of B. cereus likely resembles that of $B$. subtilis. In both bacteria, we identified genes or operons encoding NADH dehydrogenases (yumB, yjlD, yutJ, and $y r k E)$, succinate dehydrogenase $(s d h A B C)$ potentially functioning as a fumarate reductase, complex III (qcr $A B C)$, proton-pumping terminal oxidases such as cytochrome aa 3 quinol oxidase $(q o x A B C D)$ and cytochrome $c$ oxidase $(c t a D E F)$, and non-proton-pumping cytochrome $b d$ quinol oxidases $(c y d A B)$. We also showed that both the cytochrome $c$ and quinol branches of the respiratory chain coexist in B. cereus independently of oxygen availability (41). In the absence of $\mathrm{O}_{2}$ or other external electron acceptor (such as nitrate), ATP synthesis occurs at the level of substrate phosphorylation and the demand for redox neutrality is met by electron transfer from reducing equivalents (such as $\mathrm{NADH}$ ) to an internal electron 


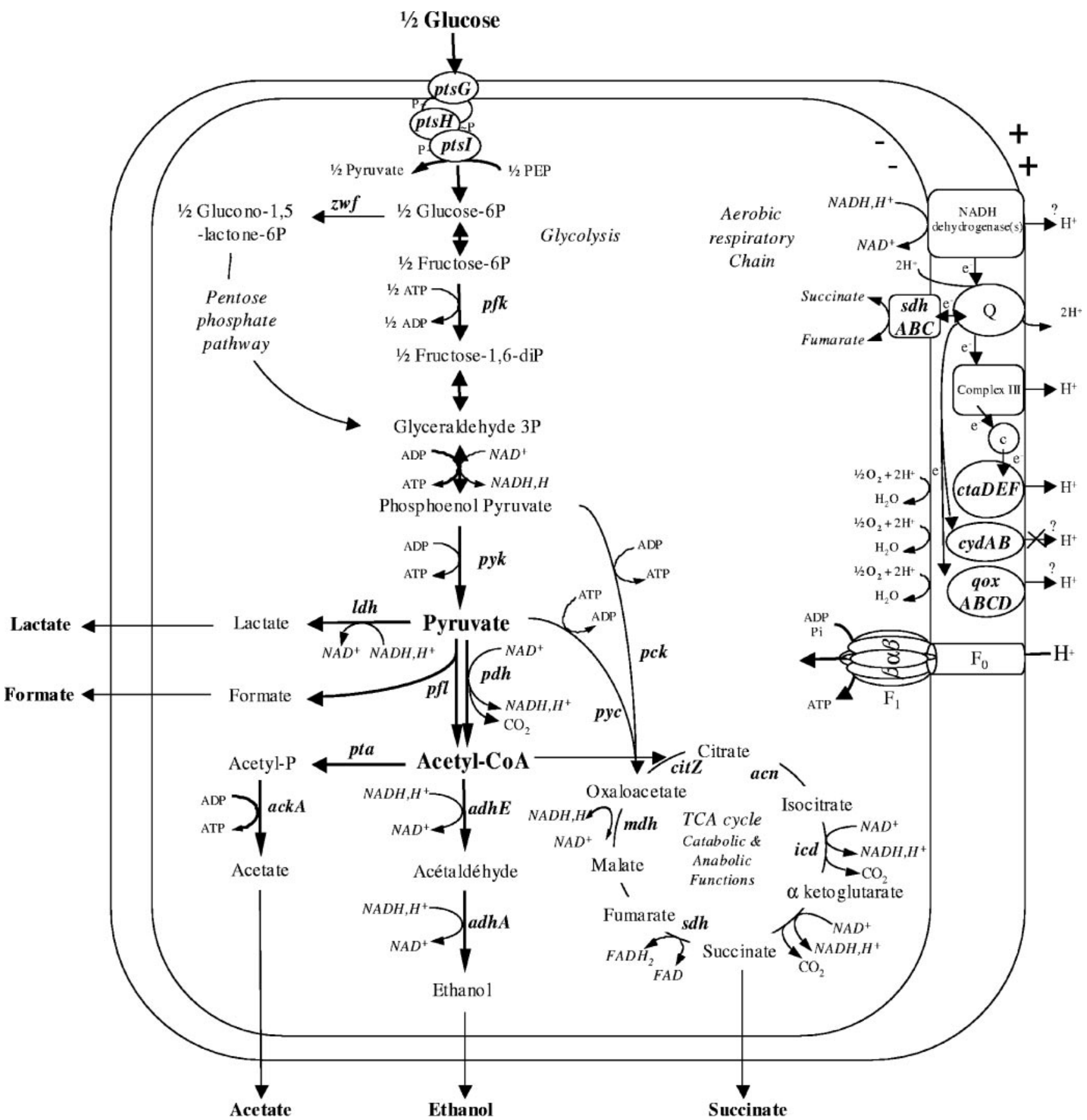

FIG. 1. Major routes of the anaerobic and aerobic catabolic pathways in Bacillus cereus. For clarity, catabolic enzymes are indicated by their gene names. Gene names and functions are described in Table 1. Q, (mena)quinone.

acceptor (such as pyruvate or acetyl coenzyme A). When growing in $\mathrm{pH}$-controlled batch cultures $(\mathrm{pH}=7.2)$, the latter results in a mixed acid fermentation with lactate, acetate, formate, ethanol, succinate, and traces of 2,3 butanediol as its typical products. The relative rate of formation of these products is influenced by the ORP of the growth medium (55). Enzymes of each catabolic pathway are regulated at the kinetic level as well as at the level of transcription. In B. subtilis, the two-component regulatory ResDE system is one of the major controlling factors of catabolic gene expression in fermentative growth $(9,33)$ and in microaerobic and aerobic growth $(19,32$, 49). It consists of a membrane-bound histidine sensor kinase (ResE) and a cytoplasmic response regulator (ResD). ResE perceives signals related to oxygen limitation and undergoes autophosphorylation at a conserved histidine residue. The level of ResD phosphorylation is determined by the balance between the two activities possessed by ResE, as phosphate donor for ResD and as a phosphatase of phosphorylated 
ResD. The activity of ResD as a transcriptional activator is modulated by the level of phosphorylation, which is higher under anaerobic than under aerobic growth conditions (34). Unlike $B$. cereus, $B$. subtilis is not typically pathogenic, and therefore the importance of ResDE in both metabolism control and virulence factor regulation could not be described. However, data obtained with the related pathogen Staphylococcus aureus revealed that a ResDE homolog was required for regulation of virulence under low-oxygen conditions (53). For these reasons, we searched homologs of the $B$. subtilis ResDE system in $B$. cereus. In the work presented here, we describe the res $D E$ gene pair's transcriptional organization of the foodborne pathogen F4430/73 strain (47) and its high degree of similarity to that of $B$. subtilis. The res $D E$ and res $E$ mutants were constructed and analyzed for their effects on growth, glucose catabolism, and enterotoxin production in response to oxygen availability and ORP of the medium under anaerobiosis. Finally, we report that the putative two-component system encoded by res $D E$ may function in $B$. cereus as a signal transduction system to coregulate metabolism and enterotoxin expression under low-ORP anaerobic conditions.

\section{MATERIALS AND METHODS}

Strains and growth conditions. Escherichia coli strains were propagated in Luria-Bertani medium. B. cereus F4430/73 wild-type (47) and mutants were grown in the synthetic MOD medium supplemented with $30 \mathrm{mM}$ glucose as a carbon source $(41,55)$. When required, antibiotics were used at the following concentrations: $50 \mu \mathrm{g}$ of ampicillin $\mathrm{ml}^{-1}$ for E. coli and $5 \mu \mathrm{g}$ of erythromycin $\mathrm{ml}^{-1}$ for B. cereus.

B. cereus cells were grown in a 2-liter bioreactor (Discovery 100; Inceltech, Toulouse, France). Temperature was maintained at $34^{\circ} \mathrm{C}$, and $\mathrm{pH}$ was maintained at 7.2 by the automatic addition of $2 \mathrm{~N} \mathrm{KOH}$. The regulated batch was equipped with a Mettler Toledo polarographic oxygen electrode coupled with a feedback regulation to maintain the set point dissolved oxygen tension value $\left(\mathrm{pO}_{2}\right)$ by air sparging and agitation speed (10). Sparging the bioreactor with air alone set a $\mathrm{pO}_{2}$ value of $100 \% \cdot \mathrm{pO}_{2}$ values of 21 and $1 \%$ were obtained by sparging the bioreactor with air balanced with pure nitrogen gas. In addition, $\mathrm{N}_{2}$ flow was adjusted manually during growth to compensate for fluctuations $5 \%$ higher than the theoretical set value. $\mathrm{A} \mathrm{pO}_{2}$ of $0 \%$ was obtained by continuously flushing the medium at $20 \mathrm{ml} \mathrm{h}^{-1}$ with either pure $\mathrm{N}_{2}$ gas previously passed through a Hungate column or with pure $\mathrm{H}_{2}$ gas. As previously described (55), ORP was measured by using a redox-combined electrode $(\mathrm{AgCl}$; Mettler Toledo), and the values were corrected according to the reference electrode value $\left(E_{\text {ref }}=200 \mathrm{mV}\right.$ at $\left.34^{\circ} \mathrm{C}\right)$. Each bioreactor was inoculated with a subculture grown overnight under $\mathrm{N}_{2}$-generated anaerobiosis in such a way that initial optical density at $560 \mathrm{~nm}\left(\mathrm{OD}_{560}\right)$ was equal to 0.02 .

Analytical procedures and physiological parameters. B. cereus growth was monitored spectrophotometrically at $560 \mathrm{~nm}$ and calibrated against cell dry weight measurements, as previously described (10). The specific growth rate $(\mu)$ was determined by using the modified Gompertz equation $(14,56,57)$. For substrate, by-product, and enterotoxin determinations, a 4-ml sample was centrifuged twice at $10,000 \times g$ for $3 \mathrm{~min}$ at $4^{\circ} \mathrm{C}$, and the supernatants were frozen at $-80^{\circ} \mathrm{C}$ until analysis. Glucose, lactate, ethanol, formate, acetate, and succinate concentrations were determined by using commercial enzymatic kits (Diffchamb, Lyon, France; R-Biopharm, Saint-Didier au Mont-d'Or, France; and Roche, Meylan, France). The specific consumption rate for glucose $\left(q_{\text {glucose }}\right)$, defined as the differential change in glucose concentration with time, was calculated from the equation $q_{\text {glucose }}=d$ [glucose $] / X(d t)$, where $X$ is the biomass concentration (in grams liter ${ }^{-1}$ ) and $t$ is time (in hours). The productions of enterotoxins $\mathrm{Hbl}$ and Nhe were quantified from culture as previously described (55). The amounts of $\mathrm{Hbl}$ produced were determined from the titer, which was defined as the reciprocal of the highest dilution of crude supernatant that gave an Hbl-dependent agglutination signal. The amounts of Nhe were estimated by measuring the $\mathrm{OD}_{420}$ (one unit was defined as one unit at $420 \mathrm{~nm}$ ). Specific enterotoxin production was defined as the amount produced per gram of cell dry mass ( $\left.\mathrm{U} \mathrm{g}^{-1}\right)$.

For reverse transcription-PCR (RT-PCR) assays, crude cell extracts were prepared from pellets obtained from 200-ml culture aliquots harvested at the mid-exponential growth phase $\left(\mu=\mu_{\max }\right)$. Total RNA was isolated from these pellets by using an RNeasy minikit (QIAGEN, Inc., France) according to the manufacturer's instructions with additional on-column DNase I digestion to eliminate genomic DNA contamination.

Cloning of the B. cereus resDE locus. The genome sequence database of the ATCC 14579 strain (www.integratedgenomics.com) was used to construct primers (5'-TGGGATCCAAAAGAGGTTTG-3' and 5'-TACCATCATGGCCTTG AACA-3') for amplification and cloning of the 2.91-kbp resDE locus of the $B$. cereus F4430/73 strain into the TA cloning vector pCR-TOPO (Invitrogen, Cergy-Pontoise, France). Sequencing was performed by MWG-Biotech (Courtaboeuf, France).

Construction of resDE and resE mutants. To construct insertional inactivation mutants, internal fragments of the resD and resE gene were first amplified by using the primer pair 5'-GCCGAAGCTTTTCGTGAGAAGAAAGCGACA-3' and $5^{\prime}$-CGCGGATCCGCAGTAACACGGTGTGCATC-3' and the primer pair 5'-CGTCTTGAAAAGATCCGTCA-3' and 5'-AAATCAACCGTTAACGCAA C-3', respectively, and cloned into the TA cloning vector pCR-TOPO (Invitrogen, Cergy-Pontoise, France). Recombinant plasmids were digested with EcoRI and NotI in parallel with the pMUTIN4 vector (51). After heat inactivation of the enzymes, fragments and plasmid were mixed for ligation. The ligation mixtures were used to transform competent cells of E. coli SCS110 (Stratagene, La Jolla, CA). Recombinant plasmids were extracted and then introduced into $B$. cereus F4430/73 by electroporation (29). The homologous recombination that resulted in a single crossover event was verified by PCR and Southern hybridization (data not shown).

Detection of the bicistronic resDE suboperon by RT-PCR. Portions of resA, res $C$, res $D$, resE, and the res $C D$ intergenic region were amplified by RT-PCR using the Titan One-Tube RT-PCR system according to the manufacturer's protocol (Roche). The primers used for $\operatorname{res} A$, resD, and resE amplification were identical to those used in real-time PCR experiments (Table 1). A portion of resC was amplified by using the forward primer 5 '-GGGTCATAAATGGGCAAAT G-3' and the reverse primer 5'-TCGCTAAAATGGCTTGTCCT-3'. The primer pair used for RT-PCR through the res $C D$ intergenic region was $5^{\prime}$-TGGGATC CAAAAGAGGTTTG-3' (forward) and 5'-GCAGTAACACGGTGTGCATC-3' (reverse). To check whether contaminating chromosomal DNA was present, each sample was tested in control reactions that did not contain reverse transcriptase.

Relative quantification of gene expression using SYBR green real-time PCR. Real-time RT-PCR was performed using SYBR Green technology on a LightCycler Instrument (Roche) as previously described (10). The various oligonucleotide primer sets are shown in Table 1. The mRNA level changes of each gene were normalized to the mRNA level of the unregulated ssu gene encoding 16S RNA and quantified by using the mathematical model established by Pfaffl (38). Two independent cultures were performed for all strains and conditions. Two RNA samples taken at $\mu=\mu_{\max }$ of a batch culture were analyzed in parallel. Therefore, the datum points for each gene transcript are an average of four measurements. The standard deviation was found to be approximately constant for the various genes tested, and the mean standard deviation for the mRNA levels was found to be $\pm 35 \%$ (data not shown). Transcript ratios were considered to be significantly different when differing by at least two standard deviations (i.e., $\leq 0.5$ or $\geq 2$ ). Under these conditions, the probability that the observed changes for a transcript were not due to experimental error is $95 \%$.

Nucleotide sequence accession number. The DNA sequence corresponding to the resDE locus amplified from $B$. cereus F4430/73 was deposited in GenBank under accession no. DQ402422.

\section{RESULTS}

Identification and sequence analysis of the $B$. cereus res $D E$ locus. Analysis of the $B$. cereus ATCC 14579 genome identified one locus orthologous to the resDE pair of B. subtilis (ERGO; Integrated Genomics, Inc.). Sequence analysis indicated that res $D E$ genes of $B$. cereus, such as the res $D E$ gene pair of $B$. subtilis, could compose a transcriptional unit included into a larger operon. The three upstream genes $\operatorname{res} A, \operatorname{res} B$, and res $C$ encoded products showing similarities to cytochrome $c$ biogenesis proteins (Fig. 2A).

The resE gene of $B$. cereus encoded a predicted protein of 591 amino acids with a calculated mass of $66.4 \mathrm{kDa}$, which 
TABLE 1. Gene-specific primers for real-time PCR

\begin{tabular}{|c|c|c|c|c|}
\hline \multirow{2}{*}{ Gene } & \multirow{2}{*}{$\begin{array}{c}\text { GenBank } \\
\text { accession no. }\end{array}$} & \multirow{2}{*}{ Putative gene product and function ${ }^{a}$} & \multicolumn{2}{|r|}{ Primer pairs $\left(5^{\prime} \rightarrow 3^{\prime}\right)$} \\
\hline & & & Orientation $^{b}$ & Sequence \\
\hline \multirow[t]{2}{*}{ ackA } & RZC02436 & Acetate kinase & $\mathrm{F}$ & GGTTTCCACGGAACTTCTCA \\
\hline & & & $\mathrm{R}$ & AAGTGCTACTTTCGCACGGT \\
\hline \multirow{2}{*}{$\operatorname{adh} A$} & RZC01378 & Alcohol dehydrogenase & $\mathrm{F}$ & CAGTACGTGCTTGCGGTAAA \\
\hline & & & $\mathrm{R}$ & CGCCCTTGAATTCTACCTTG \\
\hline \multirow[t]{2}{*}{ adhE } & RZC03282 & Acetaldehyde dehydrogenase & $\mathrm{F}$ & TTTGACGTCGAACCAGATCC \\
\hline & & & $\mathrm{R}$ & GGTGTCACTTCTGATCCCGT \\
\hline \multirow[t]{2}{*}{ res $A$} & RZC03448 & Cytochrome $c$ biogenesis protein & $\mathrm{F}$ & CGAAATCGGAAAAGAAGCAC \\
\hline & & & $\mathrm{R}$ & CAAAAAGCTTGTCGGTAAAG \\
\hline \multirow[t]{2}{*}{$\operatorname{res} D$} & DQ402422 & Response regulator & $\mathrm{F}$ & TTCGTGAGAAGAAAGCGACA \\
\hline & & & $\mathrm{R}$ & GCAGTAACACGGTGTGCATC \\
\hline \multirow[t]{2}{*}{ resE } & DQ402422 & Sensor kinase & $\mathrm{F}$ & CGTCTTGAAAAGATCCGTCA \\
\hline & & & $\mathrm{R}$ & AAATCAACCGTTAACGCAAC \\
\hline \multirow{2}{*}{ citB } & RZC04993 & Aconitase hydratase & $\mathrm{F}$ & CAATCGCAGCAAACGACTTA \\
\hline & & & $\mathrm{R}$ & GCTGATGGCCAAATATCGTT \\
\hline \multirow[t]{2}{*}{$\operatorname{cit} Z$} & RZC01265 & Citrate synthase & $\mathrm{F}$ & TGATCCACGTGCAAAACACT \\
\hline & & & $\mathrm{R}$ & CGGACGAATTAAACGGTTGT \\
\hline \multirow[t]{2}{*}{$\operatorname{cta} B$} & RZC05864 & Cytochrome $c$ oxidase polypeptide II & $\mathrm{F}$ & TGCAGCGATGTTAATTTTCG \\
\hline & & & $\mathrm{R}$ & ACGGCAACAAGCAAGAAAT \\
\hline \multirow[t]{2}{*}{$\operatorname{cyd} A$} & RZC03824 & Cytochrome $d$ ubiquinol oxidase subunit I & $\mathrm{F}$ & TGCTCATGGAACAGAATGGA \\
\hline & & & $\mathrm{R}$ & CTTCCGATAACGAAAGGCAA \\
\hline \multirow[t]{2}{*}{$h b l C$} & AY247972 & Hemolysin BL component L2 & $\mathrm{F}$ & ATACGCAACGGCAAATCAAT \\
\hline & & & $\mathrm{R}$ & СТTCATCAGGTCATACTCTT \\
\hline \multirow[t]{2}{*}{$i c d$} & RZC01263 & Isocitrate dehydrogenase & $\mathrm{F}$ & GCAAGGATCTCCAGAAGCAG \\
\hline & & & $\mathrm{R}$ & CGATGATTTTTCCAGCCACT \\
\hline $\operatorname{ldh} A$ & RZC01053 & Lactate dehydrogenase I & $\mathrm{F}$ & AGGAGCGAGTGCGAAGATTA \\
\hline & & & $\mathrm{R}$ & AATTGGCTTTCCACCAACAG \\
\hline$l d h B$ & RZC06846 & Lactate dehydrogenase II & $\mathrm{F}$ & CCATGTTTCCGTTGGTATCC \\
\hline & & & $\mathrm{R}$ & TTAAAACAGCAGGTACCCCG \\
\hline $\operatorname{ldh} C$ & RZC05932 & Lactate dehydrogenase III & $\mathrm{F}$ & CCATGTTTCCGTTGGTATCC \\
\hline & & & $\mathrm{R}$ & TTAAAACAGCAGGTACCCCG \\
\hline nheA & DQ019312 & Nonhemolytic enterotoxin component A & $\mathrm{F}$ & AGGCGAATGTACGAGAATGG \\
\hline & & & $\mathrm{R}$ & TCCACTTGATCCTTGCAGTG \\
\hline pckA & RZC07251 & Phosphoenolpyruvate carboxylase A & $\mathrm{F}$ & TCTCAACTTGCTTCGGTTCA \\
\hline & & & $\mathrm{R}$ & CCCAAGTTTGTTCAGGCATT \\
\hline$p d h A$ & RZC01920 & Pyruvate dehydrogenase E1 alpha subunit & $\mathrm{F}$ & TTCGCACTTGAAGCAGAAGA \\
\hline & & & $\mathrm{R}$ & TGAATGCACCTGCAAAGTTC \\
\hline$p f l$ & RZC03049 & Pyruvate formate lyase & $\mathrm{F}$ & GCGGTGGAGAGCCATTATTA \\
\hline & & & $\mathrm{R}$ & TACGTGTCGTACCCAAATCG \\
\hline plcR & AY247971 & Phospholipase $\mathrm{C}$ regulator & $\mathrm{F}$ & TCCAGCAATTTCTTCAATGG \\
\hline & & & $\mathrm{R}$ & TCGGCATGATATTTCAATCG \\
\hline pta & RZC05214 & Phosphate acetyltransferase & $\mathrm{F}$ & CAGTTCGTCCAGCACTTCAA \\
\hline & & & $\mathrm{R}$ & TCTGGAGATTTCGCAGAACC \\
\hline ptsG & RZC06596 & PTS system, glucose-specific II ABC component & $\mathrm{F}$ & TGCAATTGAGCCAACTGAAG \\
\hline & & & $\mathrm{R}$ & GCTACAAGCGCTTCAAAACC \\
\hline ptsH & RZC06595 & PTS system, phosphocarrier protein HPr & $\mathrm{F}$ & GAAAATCCAAAACGGCGATA \\
\hline & & & $\mathrm{R}$ & CGCTTCGAACTGCTCTTCTT \\
\hline pycA & RZC08441 & Pyruvate carboxylase & $\mathrm{F}$ & GCAATTGACGCTGTACGAGA \\
\hline & & & $\mathrm{R}$ & ACGATATCAACACCCGCTTC \\
\hline pykF & RZC04966 & Pyruvate kinase II & $\mathrm{F}$ & GTACAATTGGACCCGCAAGT \\
\hline & & & $\mathrm{R}$ & TGCTCTCCCTTCACTTCACC \\
\hline pykA & RZC01414 & Pyruvate kinase I & $\mathrm{F}$ & CTGCAATCGTAGCTCCAACA \\
\hline & & & $\mathrm{R}$ & CCGATTAGACCTGCATCCAT \\
\hline qoxA & RZC01327 & Cytochrome $a a_{3}$ quinol oxidase polypeptide II & $\mathrm{F}$ & CCCAGCTGGTGTACCAATTC \\
\hline & & & $\mathrm{R}$ & CGCACTACGGCCTAGGTAAG \\
\hline$s d h A$ & RZC07054 & Succinate dehydrogenase flavoprotein subunit & $\mathrm{F}$ & AACAATGCGGTTTCTTACGG \\
\hline & & & $\mathrm{R}$ & TGTGGATCGATGAACGCTAA \\
\hline ssu & D16266 & 16S rRNA & $\mathrm{F}$ & GCAAGGCTGAAACTCAAAGG \\
\hline & & & $\mathrm{R}$ & TGTAGCCCAGGTCATAAGGG \\
\hline$z w f$ & RZC00583 & Glucose-6-phosphate dehydrogenase & $\mathrm{F}$ & GCAAAATTTACCCCGCACTA \\
\hline & & & $\mathrm{R}$ & GCGTTTCCATCCATCTGTTT \\
\hline
\end{tabular}

\footnotetext{
${ }^{a}$ The gene names and functions are essentially those given in the literature (22).

${ }^{b} \mathrm{~F}$, forward; R, reverse.
}

shares $79 \%$ identity with the ResE histidine kinase of $B$. subtilis. In common with its closest homolog, B. cereus ResE displayed all of the typical characteristics of the histidine kinase protein family. The res $D$ gene encoded a protein of 238 amino acids with a calculated molecular mass of $27.4 \mathrm{kDa}$, and the deduced protein shared over $52 \%$ identity with the ResD of $B$. subtilis; both proteins belong to the OmpR family of response regulators and contain a winged helix-turn-helix motif. 


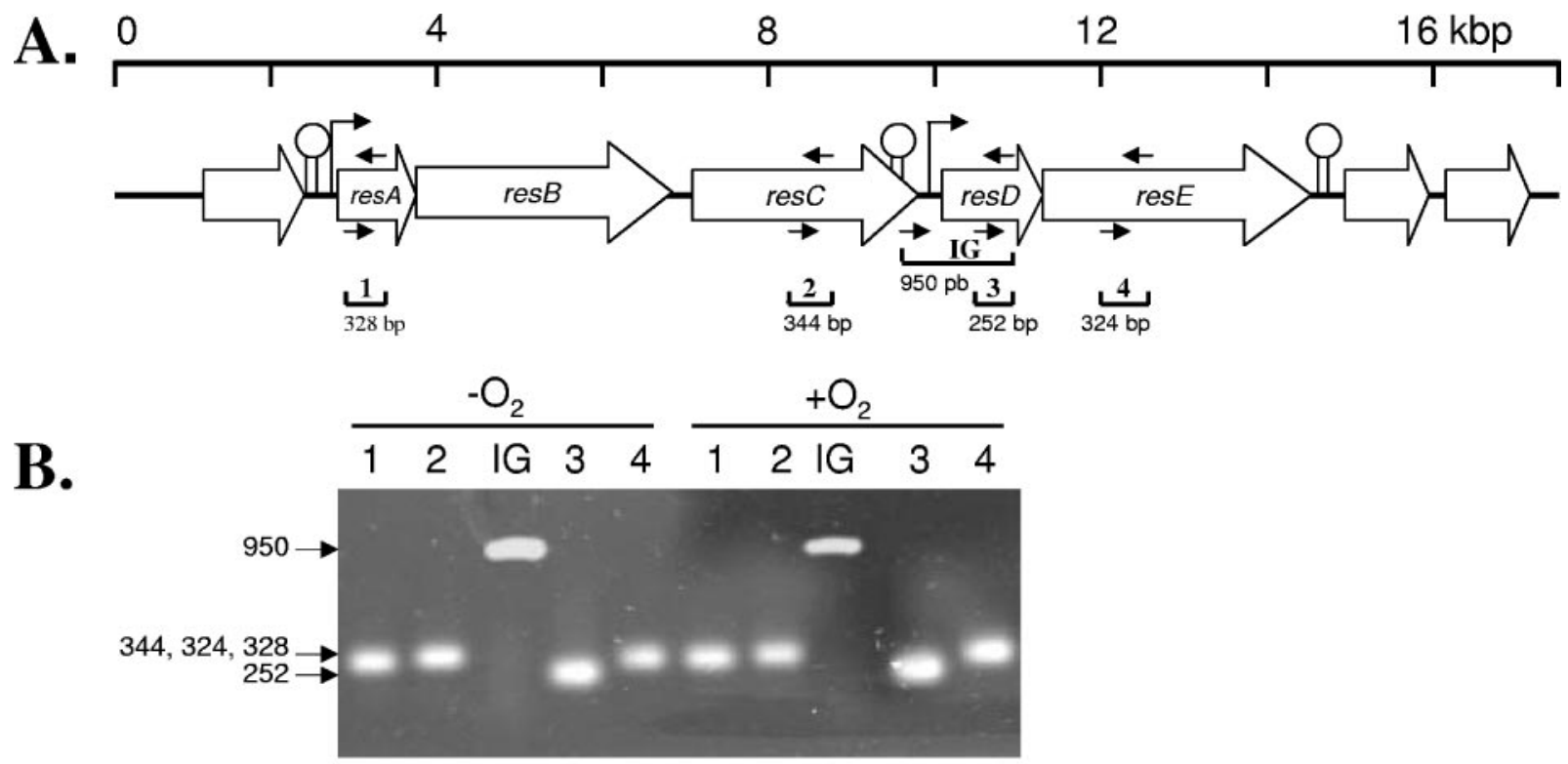

ResE (591 aa)
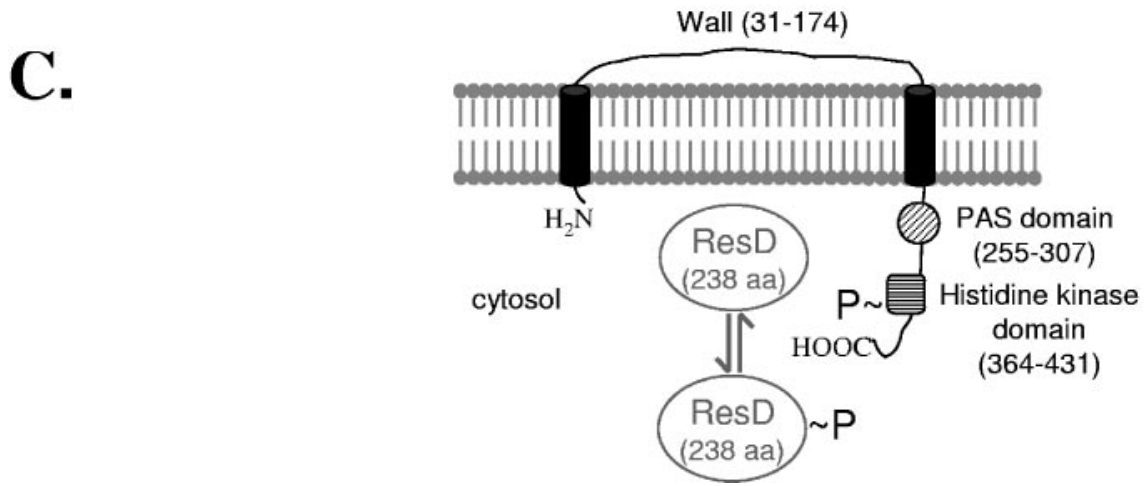

FIG. 2. (A) Gene organization of the B. cereus chromosome region containing resDE. Arrowhead and stem-loop-type structures indicate putative promoters for $\sigma_{\mathrm{A}}$ showing the directions of transcription and of the $\rho$-independent transcriptional terminators. The arrows show the positions and directions of the gene-specific primers used in RT-PCR to amplify internal regions within res $A$ (1), resC (2), resD (3), and resE (4) and the intergenic region between $\operatorname{res} C$ and $\operatorname{res} D$ (IG). (B) RT-PCR analysis for detecting res $A$ (1), resC (2), resDE (3), and resE (4) transcripts and the intergenic region (IG) between resC and resDE in strain $\mathrm{F} 4430 / 73$ grown under $\mathrm{N}_{2}$ anaerobiosis $\left(\mathrm{pO}_{2}=0 \%\right)$ or full aerobiosis $\left(\mathrm{pO}_{2}=\right.$ $100 \%$ ). Labels on the left indicate the size of the amplified fragments in base pairs. (C) Predicted membrane topology of the kinase sensor ResE. Putative transmembrane domains (amphipathic helices) are depicted as black rectangles. Putative PAS and histidine kinase cytoplasmic domains are also indicated. Coordinates of the amino acid residues that are expected to face the cell wall and constitute the two cytoplasmic domains are indicated in parentheses. Phosphoryl transfer from ResE to the response regulator ResD is also shown.

Given that the B. cereus ATCC 14579 strain was not recognized as a diarrheal strain, we focused on the food-borne pathogenic $B$. cereus F4430/73 strain, which belongs to the same genetic group (20). In order to determine whether the res $D E$ gene pair showed similar genetic organization in the two strains, we first performed RT-PCR experiments to verify that the res $D E$ gene pair could form a five-gene operon with res $A B C$ in the $\mathrm{F} 4430 / 73$ strain. Experiments were performed on total RNA isolated from F4430/73 cells grown under aerobic $\left(\mathrm{pO}_{2}=100 \%\right)$ and anaerobic conditions (generated under $\mathrm{N}_{2}$ atmosphere, $\mathrm{pO}_{2}=0 \%$ ). The location of the primer pairs used for the detection of res $A, \operatorname{res} C$, res $D$, and res $E$ and the intergenic region between res $C$ and res $D$ are given in Fig. 2A. As shown in Fig. 2B, RT-PCR amplification generated products of the expected size for all tested genes, as well as for the intergenic region. In control reactions, PCR products were not found when the reverse transcription reaction was run without reverse transcriptase (data not shown). These results indicate that transcript from $\operatorname{res} A$ does not invariably terminate after $\operatorname{res} C$ and thus that all five genes from res $A$ to res $E$ could be cotranscribed as a single transcript of $\sim 7.8 \mathrm{~kb}$. The RTPCR products were quantified by using real-time PCR technology, and we found that under both conditions mRNA for the intergenic region was almost 3-fold less abundant than for both $\operatorname{res} D$ and $\operatorname{res} E$, indicating that these two genes may be expressed from a second minor transcript of $\sim 2.7 \mathrm{~kb}$. We then selected the 2.91-kbp fragment encompassing the end of the res $C$ gene and the entire res $D E$ gene pair of $B$. cereus $\mathrm{F} 4430 / 73$ 
(Fig. 2A) for cloning and sequencing. Inspection of the 2.91kbp fragment sequence revealed only two nucleotide substitutions between the ATCC 14579 and F4430/73 strains, which are localized in the $3^{\prime}$-terminal region of $r e s E$ (data not shown). Consequently, the predicted amino acid sequence of ResD was the same in the two strains. In contrast, the predicted amino acid sequence of ResE differed between F4430/73 and ATCC 14579 strains by an aspartic residue instead of glycine at position 418 and by a methionine residue instead of threonine at position 509, respectively. These amino acid substitutions did not affect the predicted functional domain of ResE (Fig. 2C).

Construction of resDE and resE mutants of $B$. cereus $\mathrm{F} 4430$ / 73. The res $D$ and res $E$ genes were inactivated in $B$. cereus F4430/73 through a single-crossover event mediated by the suicide vector pMUTIN4 containing a 252-bp fragment of res $D$ (corresponding to codons 70 to 154) or a 324-bp fragment of resE (corresponding to codons 361 to 469), respectively (51). Integration of pMUTIN4 within each gene was confirmed by PCR analysis and Southern blotting (data not shown). With RNA isolated from each of the two mutant strains, resE did not have transcripts that were detectable by RT-PCR (data not shown). Therefore, by inactivating res $D$, we also abolished res $E$ transcription. Finally, we constructed two kinds of mutant strains: (i) a res $D E$ mutant that would encode a truncated ResD lacking the final 84 amino acids of the 238-residue protein (i.e., lacking the putative DNA-binding domain) and would not synthesize ResE and (ii) a resE mutant strain that would synthesize native ResD and a truncated ResE lacking the final 100 amino acids of the 569-residue protein (i.e., lacking the putative histidine kinase domain).

Impact of res $D E$ and res $E$ mutations on aerobic, microaerobic, and anaerobic growth of $\boldsymbol{B}$. cereus. The growth features of the res $D E$ and resE mutants were compared to those of the parental F4430/73 strain under distinct oxygenation conditions, i.e., full aerobiosis $\left(\mathrm{pO}_{2}=100 \%\right), 21 \%$ aerobiosis $\left(\mathrm{pO}_{2}=\right.$ $21 \%)$, microaerobiosis $\left(\mathrm{pO}_{2}=1 \%\right)$, and anaerobiosis $\left(\mathrm{pO}_{2}=\right.$ $0 \%$ ). Independently of oxygen, mutants were also characterized in terms of their response to changes in extracellular oxidoreduction potential (ORP) by comparing "classical" $\mathrm{N}_{2}$ anaerobiosis (high initial ORP $=+45 \mathrm{mV}$ ) to $\mathrm{H}_{2}$ anaerobiosis (low initial ORP $=-148 \mathrm{mV}$ ).

As shown in Table 2, resDE and resE mutations did not significantly affect the growth of $B$. cereus F4430/73 under either full aerobiosis or high ORP $\mathrm{N}_{2}$ anaerobiosis. Nevertheless, we observed that the maximal specific growth rate $\left(\mu_{\max }\right)$ of res $D E$ mutant decreased $\sim 1$.4-fold at $\mathrm{pO}_{2}$ values of 1 and $21 \%$ without a significant change in final biomass. This moderate growth impairment was not relative to glucose consumption, suggesting perturbation of the respiratory pathways. In accordance with this hypothesis, we observed a higher oxygen demand of the resDE mutant at a $\mathrm{pO}_{2}$ of 1 and $21 \%$. Indeed, an increase of the oxygen content in the input gas was needed from the start of the exponential growth phase $(2 \mathrm{~h}$ after the start of growth) with the res $D E$ mutant, whereas a twofoldlower requirement was needed later $(5 \mathrm{~h}$ after the start of growth) with the resE mutant and the wild type (data not shown). Interestingly, the $\mu_{\max }$ and final biomass of the resE mutant strain were drastically reduced $(\sim 2.5$-fold $)$ under lowORP $\mathrm{H}_{2}$ anaerobic conditions (Table 2). This was probably the

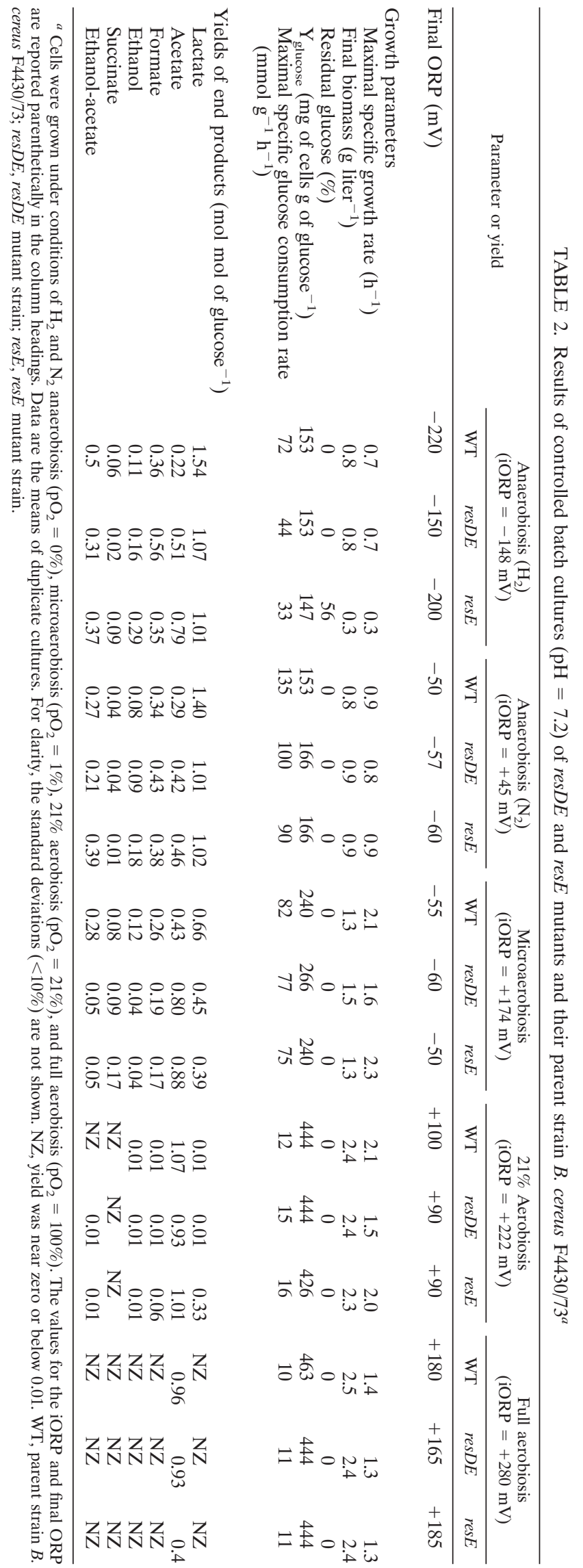


result of both lower levels and lower specific rates of glucose consumption. However, the growth yield on glucose $\left(\mathrm{Y}_{\text {glucose }}\right)$ was not affected. Thus, the resE mutation may strongly affect growth kinetics under low-ORP conditions by acting directly or indirectly on glucose uptake, although other factors may be responsible for growth arrest.

Impact of res $D E$ and res $E$ mutations on the glucose catabolism of B. cereus. As shown in Table 2, the spectra of glucose by-products are quantitatively the same as those found previously under low- and high-ORP anaerobiosis (55) and under full aerobiosis (41) in the case of the wild-type F4430/73 cells. Briefly, wild-type cells switched gradually from fully fermentative to fully respiratory metabolism as more oxygen become available, with acetate being the most persistent by-product. In fermentative conditions, low-ORP conditions promoted $\mathrm{NADH}$-dependent lactate production at the expense of ATPdependent acetate production (Table 2). In addition, the ethanol-to-acetate ratio increased when ORP decreased, i.e., when NADH availability increased (43).

The spectra of fermentation end products were significantly modified by the res $D E$ and resE mutations (Table 2). In both res $D E$ and resE mutants, acetate production was promoted at the expense of lactate under fully fermentative conditions $\left(\mathrm{pO}_{2}=0 \%\right)$, as well as at a $\mathrm{pO}_{2}$ of $1 \%$, i.e., as oxygen became strongly limiting for respiratory processes. Under strict anaerobiosis, this higher acetate production occurred concomitantly with a higher production of formate plus ethanol. However, formate production was specifically favored in the res $D E$ mutant, whereas ethanol production was specifically favored in the resE mutant. Taken together, these results indicate that $\operatorname{res}(D) E$ mutations affected carbon partitioning at the two key fermentative nodes, i.e., at the pyruvate and acetyl coenzyme A (acetyl-CoA) nodes (Fig. 1). When grown under high-ORP anaerobic conditions (Table 2), the resE mutant overproduced both ethanol and acetate and also exhibited a higher ethanolto-acetate ratio than both the res $D E$ mutant and the wild-type strain. This ratio remained unchanged under low-ORP conditions but was increased in the res $D E$ mutant as in the wild type. One explanation could be that the control of carbon flow at the acetyl-CoA node was so disturbed in the resE mutant that cells lose the ability to favor the NADH recycling ethanol pathway over the ATP generating acetate, this readjustment being required for growth under low-ORP conditions (55).

Impact of res $D E$ and resE mutations on enterotoxin synthesis. To determine the effect of res $D E$ expression on the production of enterotoxin, the specific levels of $\mathrm{Hbl}$ and Nhe were quantified at the end of batch cultures of B. cereus strains (Fig. 3). $\mathrm{Hbl}$ and Nhe productions were significantly affected in the res $D E$ mutant when grown under anaerobiosis. Moreover, the decrease caused by res $D E$ inactivation was higher under lowversus high-ORP conditions for both $\mathrm{Hbl}$ (Fig. 3A) and Nhe (Fig. 3B). These data indicate that, res $D E$ expression may play an important role in the low-ORP anaerobiosis-dependent regulation of enterotoxin synthesis. Interestingly, the resE mutation suppressed $\mathrm{Hbl}$ and Nhe production to almost undetectable levels in aerobic, microaerobic, and anaerobic conditions ( $>97 \%$ reduction compared to the parental strain). This indicates that resE product is essential for $\mathrm{Hbl}$ and Nhe synthesis when res $D$ is expressed.
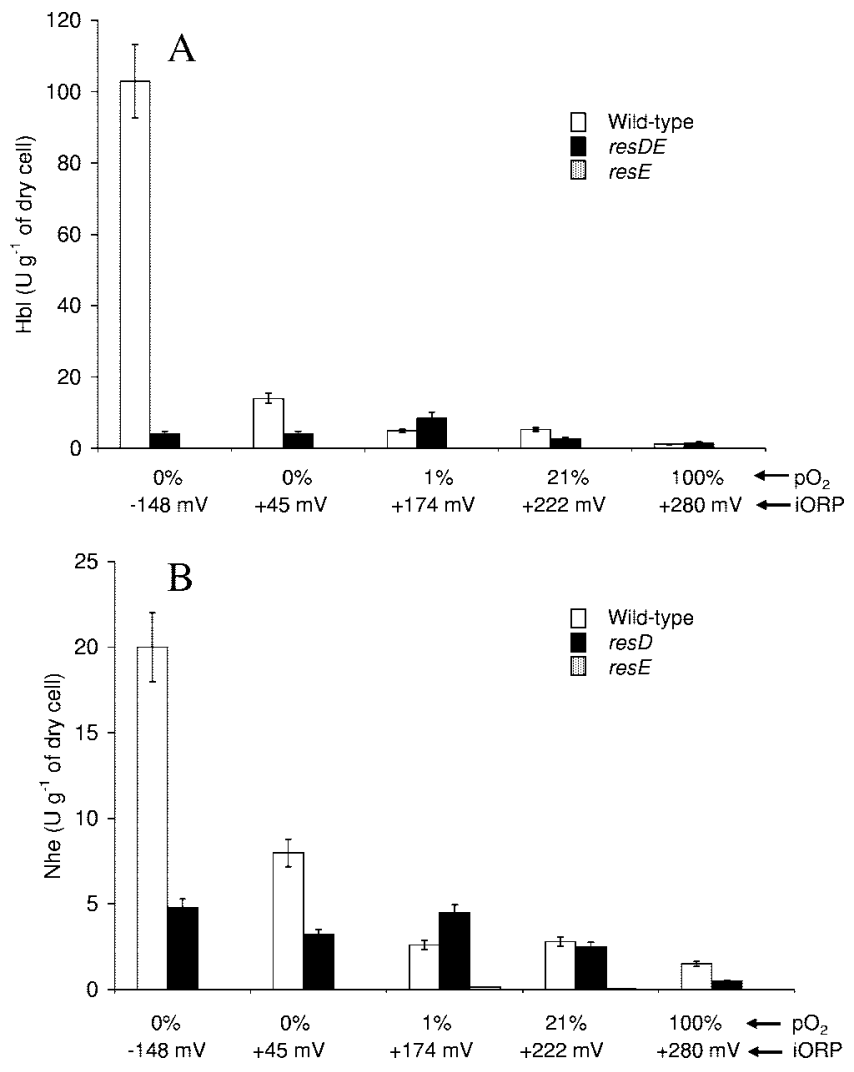

FIG. 3. Comparison of specific enterotoxin production between the res $D E$ and resE mutant strains and their parent strain B. cereus $\mathrm{F} 4430$ / 73. $\mathrm{Hbl}$ and Nhe levels were measured in culture supernatants at the end of $\mathrm{pH}$-controlled batch cultures conducted under anaerobiosis at low initial ORP $(-148 \mathrm{mV})$ and high initial ORP $(+45 \mathrm{mV})$, under microaerobiosis $\left(\mathrm{pO}_{2}=1 \%\right.$, iORP $\left.=+174 \mathrm{mV}\right), 21 \%$ aerobiosis $\left(\mathrm{pO}_{2}=21 \%\right.$; iORP $\left.=+222 \mathrm{mV}\right)$, and under full aerobiosis $\left(\mathrm{pO}_{2}=\right.$ $100 \%$; iORP $=+280 \mathrm{mV}$ ). Bars indicate the standard error of the mean.

Gene expression profiles. Using quantitative RT-PCR, we investigated the effects of $\mathrm{O}_{2}$ availability and $\mathrm{O}_{2}$-independent ORP on the transcription of both glucose catabolism genes and enterotoxin genes (Table 3). Our focus was on a single physiological state, i.e., mid-exponential growth on glucose $(\mu=$ $\left.\mu_{\max }\right)$, which is the phase with the highest transcription for all genes studied (55; data not shown). Wild-type cells sustained the highest level of res $D E$ transcript when grown under lowORP anaerobiosis. These conditions also led to the highest levels of pyruvate catabolism, anabolic tricarboxylic acid, enterotoxin gene, and $p l c R$ transcripts, a finding consistent with a fully fermentative metabolism and high enterotoxin production. Interestingly, we observed a significant change in the mRNA profile of the three genes predicted to encode L-lactate dehydrogenase (Ldh) and also a significant increase in the transcript level specific to acetaldehyde dehydrogenase (adhE) under low- versus high- ORP conditions. These variations in transcription levels were consistent with the preferential use of the pyruvate/acetyl-CoA/ethanol pathway at low ORP and indicated that the ORP-dependent regulation of carbon flux may occur at least partially at the transcriptional level. We also observed that the genes encoding respiratory chain compo- 
TABLE 3. Expression of genes involved in glucose metabolism and virulence in B. cereus F4430/73

\begin{tabular}{|c|c|c|c|c|}
\hline \multirow{4}{*}{ Function and gene } & \multicolumn{4}{|c|}{ Fold induction or repression } \\
\hline & \multirow{2}{*}{\multicolumn{2}{|c|}{$\begin{array}{l}\text { Anaerobic growth } \\
\left(\mathrm{pO}_{2}=0 \%\right)\end{array}$}} & \multicolumn{2}{|c|}{ Aerobic growth } \\
\hline & & & \multirow{2}{*}{$\frac{\mathrm{pO}_{2}=1 \%}{\mathrm{iORP}=+174 \mathrm{mV}}$} & \multirow{2}{*}{$\frac{\mathrm{pO}_{2}=21 \%}{\mathrm{iORP}=+222 \mathrm{mV}}$} \\
\hline & $\mathrm{iORP}=-148 \mathrm{mV}$ & $\mathrm{iORP}=+45 \mathrm{mV}$ & & \\
\hline $\begin{array}{l}\text { Two-component system } \\
\quad \text { res } D\end{array}$ & +143 & +4.6 & +2.0 & +2.1 \\
\hline $\begin{array}{l}\text { Glucose metabolism } \\
\text { Glucose transport }\end{array}$ & & & & \\
\hline $\begin{array}{l}p t s G \\
p t s H\end{array}$ & $\begin{array}{l}+2.0 \\
+5.2\end{array}$ & $\begin{array}{r}+2.1 \\
1.0\end{array}$ & $\begin{array}{l}-1.2 \\
-2.5\end{array}$ & $\begin{array}{l}-1.2 \\
-2.5\end{array}$ \\
\hline $\begin{array}{l}\text { Pentose phosphate pathway } \\
z w f \\
\text { Glycolysis }\end{array}$ & +4.4 & +5.8 & -10.0 & -1.6 \\
\hline $\begin{array}{l}\text { pykA } \\
p y k F \\
p c k A \\
p y c A\end{array}$ & $\begin{array}{l}+9.1 \\
+6.8 \\
-1.4 \\
+3.3\end{array}$ & $\begin{array}{l}+1.1 \\
+2.1 \\
-1.6 \\
+1.4\end{array}$ & $\begin{array}{l}-1.4 \\
-5.0 \\
-2.5 \\
-2.0\end{array}$ & $\begin{array}{l}-2.4 \\
-5.0 \\
-3.3 \\
-2.5\end{array}$ \\
\hline $\begin{array}{l}\text { Pyruvate catabolism } \\
\text { ldhA } \\
\text { ldhB } \\
\text { ldhC } \\
\text { pfl } \\
\text { pdhA } \\
\text { pta } \\
\text { ack } A \\
\text { adhE } \\
\text { adhA }\end{array}$ & $\begin{array}{r}+23,870 \\
+7.8 \\
+46.9 \\
+94.7 \\
+6.1 \\
+15.2 \\
+12.3 \\
+348.4 \\
+10.3\end{array}$ & $\begin{array}{r}+2,083 \\
+8.4 \\
+12.3 \\
+86.8 \\
+6.9 \\
+11.6 \\
+11.2 \\
+40.1 \\
+17.8\end{array}$ & $\begin{array}{r}+1,274 \\
+3.0 \\
+4.6 \\
+53.5 \\
+4.0 \\
+7.4 \\
+6.1 \\
+5.1 \\
+3.9\end{array}$ & $\begin{array}{r}+18.0 \\
+1.8 \\
-1.2 \\
+2.2 \\
+3.3 \\
+6.9 \\
+5.0 \\
+1.2 \\
+1.3\end{array}$ \\
\hline $\begin{array}{l}\text { TCA cycle }{ }^{b} \\
\text { citB } \\
\text { cit } Z \\
\text { icd } \\
\quad s d h A\end{array}$ & $\begin{array}{r}+3.7 \\
+59.7 \\
+12.7 \\
+38.7\end{array}$ & $\begin{array}{r}+1.8 \\
+6.2 \\
+2.5 \\
+15.2\end{array}$ & $\begin{array}{r}-2.0 \\
+2.4 \\
1.0 \\
+4.6\end{array}$ & $\begin{array}{l}-2.5 \\
+1.3 \\
-1.4 \\
+4.5\end{array}$ \\
\hline $\begin{array}{l}\text { Cytochrome metabolism } \\
\quad \text { ctaB } \\
\text { cyd } A \\
\text { qox } A \\
\operatorname{res} A\end{array}$ & $\begin{array}{r}+4.2 \\
+11.1 \\
+1.2 \\
+32.4\end{array}$ & $\begin{array}{l}-3.3 \\
-1.4 \\
-5.0 \\
+1.3\end{array}$ & $\begin{array}{l}-3.3 \\
+1.8 \\
-3.3 \\
-3.3\end{array}$ & $\begin{array}{l}-5.0 \\
-3.3 \\
-5.0 \\
-5.0\end{array}$ \\
\hline $\begin{array}{l}\text { Virulence } \\
\text { Enterotoxins }\end{array}$ & & & & \\
\hline $\begin{array}{l}\text { hblC } \\
\text { nheA }\end{array}$ & $\begin{array}{l}+13.1 \\
+20.8\end{array}$ & $\begin{array}{r}+10.2 \\
+6.8\end{array}$ & $\begin{array}{l}+9.6 \\
+5.8\end{array}$ & $\begin{array}{l}+1.8 \\
+3.7\end{array}$ \\
\hline $\begin{array}{l}\text { Regulator } \\
\quad \text { plcR }\end{array}$ & +45.5 & +17.0 & +11.4 & +12.3 \\
\hline
\end{tabular}

${ }^{a}$ Controlled batch cultures were performed under anaerobic conditions $\left(\mathrm{pO}_{2}=0 \%\right)$ at low $(-148 \mathrm{mV})$ and high $(+45 \mathrm{mV})$ iORP, under microaerobic conditions $\left(\mathrm{pO}_{2}=1 \%\right)$, and under $21 \%$ aerobiosis $\left(\mathrm{pO}_{2}=21 \%\right)$. Each fold change value represents the mean value of the specific mRNA level of the anaerobic or microaerobic sample in relation to that of the full aerobic sample $\left(\mathrm{pO}_{2}=100 \%\right)$. For each experiment, two measures from two independent RNA samples taken from the mid-exponential growth phase $\left(\mu=\mu_{\max }\right)$ of the same culture were analyzed in parallel. Each datum point is an average of the results for the combined experiments. Only ratios of $\leq 0.5$ and $\geq 2$ were considered to be significant (i.e., $P \leq 0.05$ ) according to the precision of the method. "+" and " - " indicate up- and downregulation, respectively, of the genes.

${ }^{b}$ TCA, tricarboxylic acid.

nents were upregulated under low ORP. Under anaerobiosis, the increased expression of these genes has no metabolic purpose but may reflect the predominant control exerted by an ORP-sensitive regulatory system (e.g., ResDE).

Transcriptional control of glucose catabolism in resDE and res $\boldsymbol{E}$ mutants. The gene transcription profile of glucose catabolism was strongly affected in res $D E$ and res $E$ mutants grown under low-ORP anaerobiosis (Fig. 4A). Most of the catabolic genes were upregulated in resE mutant compared to the wild type, whereas they were rather downregulated in the res $D E$ mutant. Interestingly, in both mutant strains, the expression profile of the three genes encoding predicted Ldh was markedly modified, favoring $l d h B$ expression over $l d h A$ and $l d h C$ expression. Nevertheless, the levels of $l d h B$ mRNA as well as other fermentative genes (from $p f l$ to $a d h A$ ) were much higher in the resE mutant than in the res $D E$ mutant. The pattern of 
A

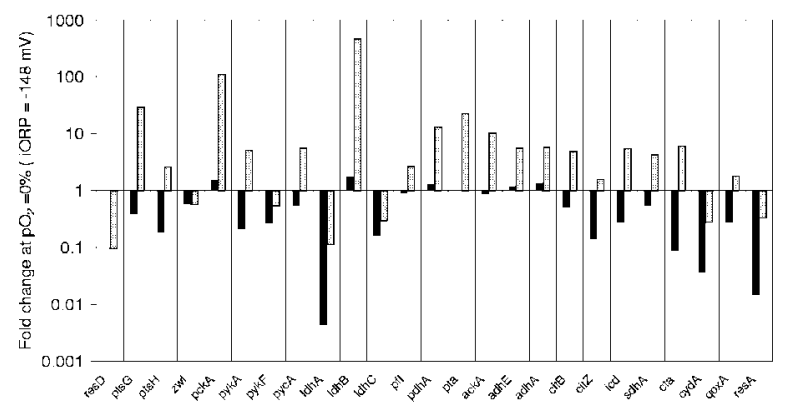

B

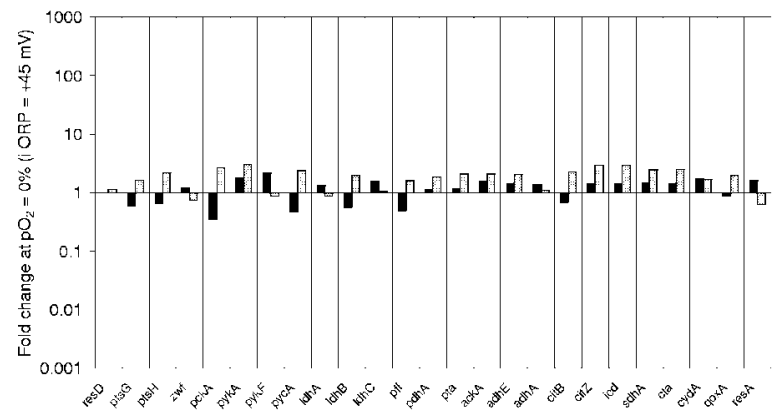

C

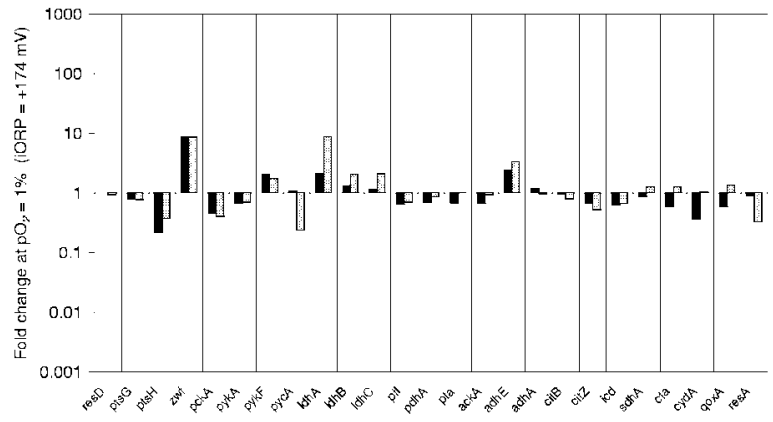

D

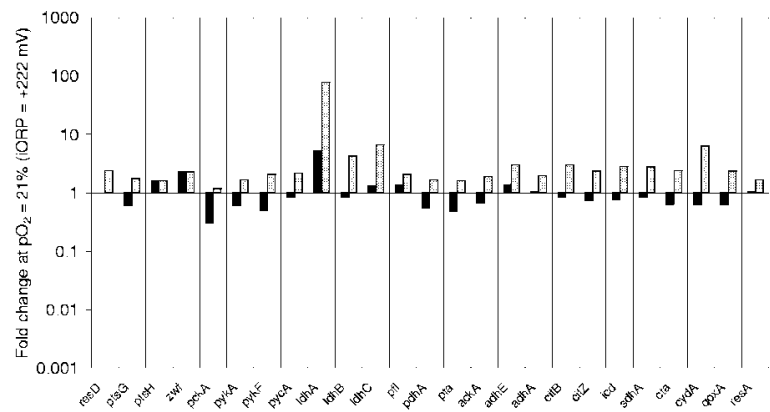

E

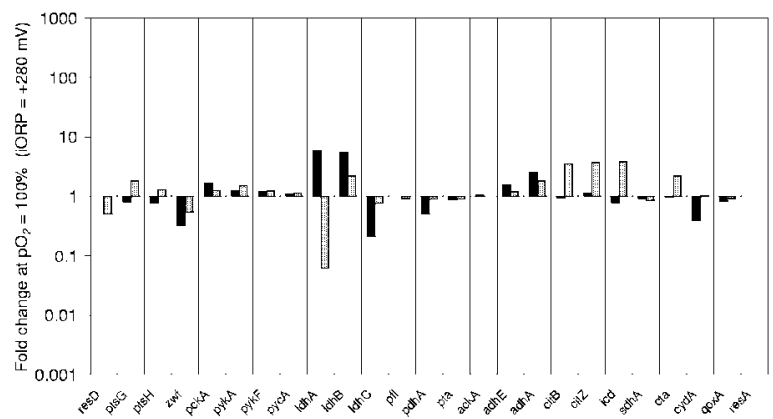

FIG. 4. Comparison of catabolic gene transcript levels between res $D E$ and resE mutant strains and the wild-type strain grown under anaerobic, microaerobic, and aerobic conditions at different initial gene deregulation correlated with carbon flux perturbation at the fermentative key nodes (i.e., the pyruvate and acetyl-CoA nodes; Table 2). Genes encoding respiratory chain components were also deregulated (Fig. 4A and B), which is consistent with a central role played by res $D E$ expression in mediating the ORP signal and the overall regulation of catabolic genes.

Under microaerobic and aerobic conditions (Fig. 4C to E), res $D E$ and resE mutations caused only moderate deregulations, as illustrated by the mRNA levels of $p t s H, z w f$, and $a d h E$. Among the fermentative genes, the only significant changes observed were the mRNA levels of the three genes encoding putative Ldh. The cydA gene, which encodes a subunit of high-affinity microaerobic non-proton-pumping cytochrome $b d$ oxidase, appeared to be downregulated in the resDE mutant. Conversely, $c t a B$, which encodes a subunit of proton-pumping cytochrome $c$ oxidase, was upregulated in the resE mutant at $\mathrm{pO}_{2}$ levels of 21 and $100 \%$. This occurred concomitantly with the upregulation of key genes in the Krebs cycle (Fig. 4D and E). Again, deregulation of respiratory genes was only moderate in both mutant strains. In conclusion, our data suggest that res $D E$ expression plays a key role in the low-ORP-dependent regulation of glucose catabolism genes, whereas its role was more moderate in the other conditions.

Transcriptional control of enterotoxin genes in resDE and $r e s E$ mutants. As shown in Fig. 5, the res $D E$ mutation significantly upregulated the transcription of $h b l$ and nhe under lowORP anaerobiosis, $21 \%$ aerobiosis, and full aerobiosis (Fig. 5A and B). The fact that protein data showed different trends (Fig. $3)$ suggests that the main control of enterotoxin production in resDE mutant did not occur mainly at the transcriptional level. In contrast, the transcription of $h b l$ and nhe was dramatically $(>90 \%)$ downregulated in resE mutant under both aerobiosis and anaerobiosis conditions. This explains why enterotoxins were almost undetectable in the culture supernatants of resE mutant. Since no correlations were observed between changes in plcR and PlcR-regulated $h b l$ and nhe transcripts in both res $D E$ and resE mutants (Fig. 5C), we assumed that the resDEdependent regulation of enterotoxin expression could not be mediated directly by PlcR.

\section{DISCUSSION}

Bacteria possess numerous two-component signal transduction systems, which facilitate adaptation to environmental conditions (48). The importance of these regulators in controlling both metabolism and virulence factors has been demonstrated

oxidoreduction potentials (iORP). The data for each gene are normalized relative to the $s s u$ transcript and are shown as the transcript ratios from the res $D E$ mutant $(\square)$ or the resE mutant (罭) strain relative to the wild type. The order of genes from pts $G$ to res $A$ is the same as that described in Table 3. Two independent experiments were performed for each strain and growth condition. For each culture, two measurements from two independent RNA samples taken from the mid-exponential growth phase $\left(\mu=\mu_{\max }\right)$ were analyzed in parallel. Each datum point is an average of the results for the combined experiments. Only ratios of $\leq 0.5$ and $\geq 2$ were considered to be significant (i.e., $P \leq$ 0.05 ) according to the precision of the method. Note that no res $D$ transcript was detected in resDE mutant. 

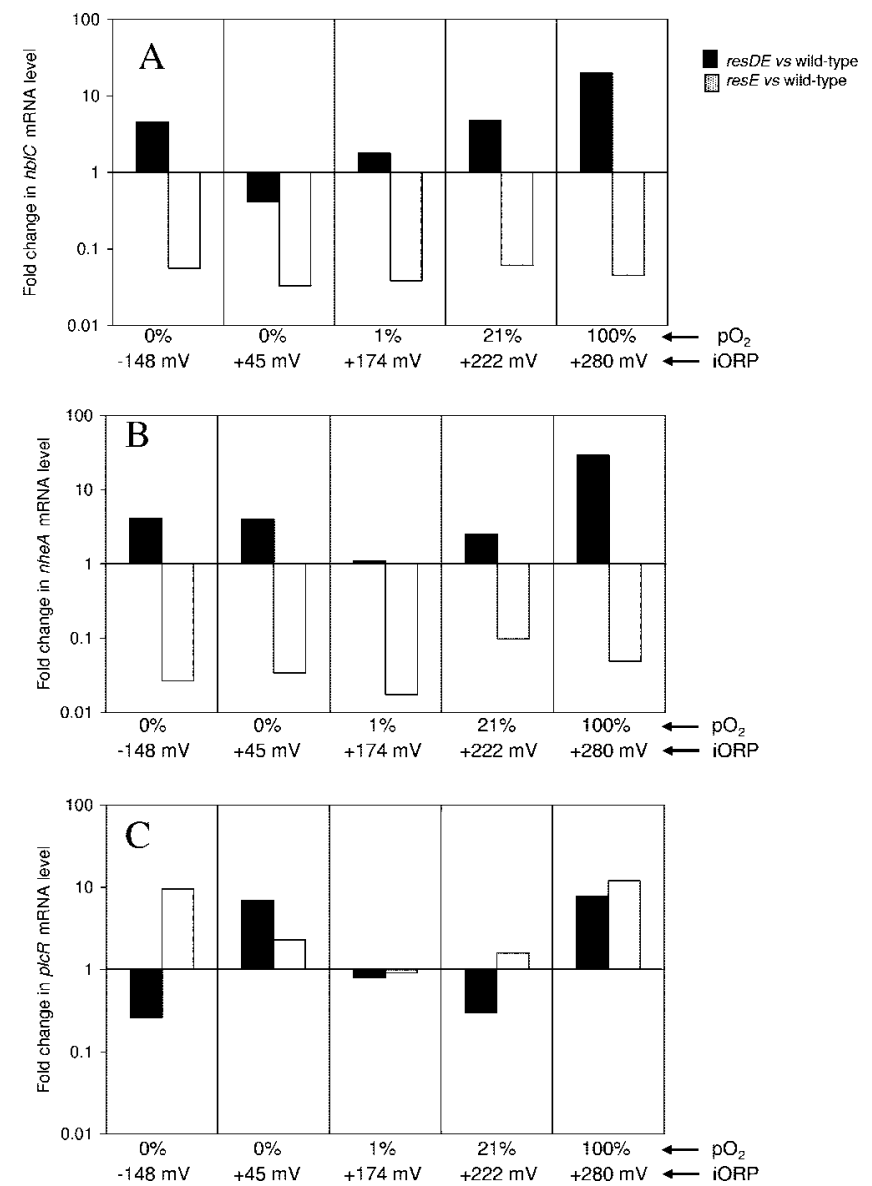

FIG. 5. Changes in specific transcript levels of the PlcR-regulated genes $h b l C(\mathrm{~A})$, nheA (B), and plcR (C) induced by resDE and resE mutations under anaerobic, microaerobic, and aerobic growth conditions at different initial oxidoreduction potentials (iORP). The change in mRNA level of each gene in resDE or resE was calculated relative to that of the wild type. Each datum point is an average of three independent measurements. RNA sampling and statistical methods were identical to those described in Fig. 4 and in Materials and Methods.

in pathogens (12), but the role of the two-component systems in $B$. cereus has yet not been studied in detail. We showed that the food-borne pathogen F4430/73 strain contains one gene pair orthologous to the res $D E$ regulatory pair of $B$. subtilis. Previous studies have revealed that the res $D E$ locus encodes a two-component transduction system ResD (response regulator)-ResE (sensor kinase), which acts as a global regulator of (micro)aerobic and anaerobic metabolism in B. subtilis (49, $54)$. The $85 \%$ identities shared by these two gene pairs further indicate that they are functionally analogous in that they elicit responses to similar stimuli through a phosphorelay cascade. In the present study, we investigated the role of the $B$. cereus ResDE system in detecting the availability of oxygen and the ORP of an oxygen-deprived medium and tuning catabolism and enterotoxin production accordingly. To evaluate the role of $B$. cereus ResDE, we used insertional mutagenesis to generate a strain lacking both active ResD and ResE (resDE mutant) and a strain lacking active ResE (resE mutant).

F4430/73 cells grown under strict anaerobic conditions have to utilize fermentation to generate sufficient energy for growth.
Thus, chemical energy is derived principally from substratelevel phosphorylation during glycolysis (Fig. 1), and the role of the tricarboxylic acid cycle is reduced to the minimum required for providing anabolic precursors (7). Under these conditions, the NADH generated must be reoxidized in order to allow glycolysis to continue; fermentation then acts to recycle $\mathrm{NAD}^{+}$ through the reduction of pyruvate into lactate and ethanol (Fig. 1). We found that under low-ORP anaerobiosis, the resE mutation led to strong changes in the transcription of genes involved in fermentation. The most striking of these changes was in the mRNA profile of the three genes encoding putative L-lactate dehydrogenase and the upregulation of genes encoding pyruvate dehydrogenase $(p d h)$, alcohol dehydrogenase $(a d h A)$, and acetate kinase $(\operatorname{ack} A)$. Lactate dehydrogenase is particularly important for $B$. cereus F4430/73 since lactate forms the bulk $(70 \%)$ of the fermentation end products (41). The res $E$ mutant seems to only partially compensate for the downregulation of $l d h A$ through the induction of $l d h B$, since NADH-dependent lactate production is decreased (by 1.5-fold compared to the wild type). In addition, we have previously shown that $B$. cereus needed to favor the NADH-recycling ethanol pathway over the ATP-producing acetate pathway in order to maintain its redox balance and grow efficiently under low-ORP conditions (Fig. 1) (55). In the resE mutant, adhA and $a c k A$ were upregulated concomitantly, and we observed that the ethanol-to-acetate ratio remained unchanged in lowversus high-ORP conditions. This suggests that resE mutant cells lost the capacity to adapt to low-ORP conditions when glucose is used as a carbon and energy source. This phenomenon provided one possible explanation for the severe growth impairment observed. However, the resE mutation also perturbed the glucose uptake rate as well as the expressions of genes encoding the phosphoenolpyruvate-carbohydrate phosphotransferase system ( $p t s G$ and $p t s H$ ) under low-ORP conditions. Thus, a slow glycolytic flux might also be responsible (even indirectly) for the observed growth arrest, but this has not yet been clearly established. Finally, we conclude that ResE may act as a redox sensor under low-ORP anaerobiosis and, as a consequence, ResD may require phosphorylation by its cognate sensor in order to regulate glucose catabolism gene transcription in response to low ORP. The redox signal activating ResE has not yet been identified but probably involves small effector molecules interacting with the PAS subdomain (50) and possibly with the extracytoplasmic region (3). Unlike res $E$, the res $D E$ mutation did not alter the growth efficiency of $B$. cereus when cultivated under low-ORP anaerobic conditions. This indicates that although it plays an important role, the ResDE system is not indispensable for B. cereus to adapt to low-ORP conditions. The complete genome sequence of $B$. cereus reveals that the organism has several global regulatory systems, all potentially responding to redox conditions (16). Among them, we can mention the redox regulators Fnr and $\mathrm{YdiH}$, which are major regulators of anaerobic growth in $B$. subtilis $(25,40)$. Furthermore, in $B$. subtilis there is a partial overlap between the Fnr, YdiH, and ResD regulated genes (40). The fact that the absence of ResD is not deleterious for F4430/73 cells suggests that key fermentative genes (such as $l d h, p f l$, and $p d h$ ) are not under the sole control of ResD. Other redox regulators could thus supply the lack of ResD to ensure the appropriate expression of enzymes in response to low-ORP 
conditions. However, results obtained with resE mutant suggest that if ResD is synthesized but not activated by ResE, this supply may not occur. One explanation is that potential binding sites for several redox regulators may overlap in the promoter region of key fermentative genes (25) and that the inactive form of ResD may bind to DNA without activating the transcription. The results obtained by RT-PCR alone, however, cannot determine which metabolic genes are directly regulated by ResDE. It is possible that lower and higher levels of transcription for many of these genes are simply due to the pleiotropic effect of the res $D E$ and resE mutations, respectively.

Both the res $D E$ and the resE mutations did not show defects in fermentative growth under high-ORP anaerobiosis. This indicates that the ResDE regulatory pathway does not govern glucose fermentation when performed under high-ORP conditions. These data differ slightly from those obtained with $B$. subtilis $(33,54)$. However, unlike B. cereus, B. subtilis does not have an efficient glucose fermentation pathway and does not possess the oxygen-sensitive pyruvate formate lyase (Pfl).

In the presence of oxygen, the transcription of respiratory genes was only moderately perturbed in both res $D E$ and resE mutants. Only the res $D E$ mutant showed impaired growth (at the kinetic level) at a $\mathrm{pO}_{2}$ of 1 and $21 \%$. This suggests that ResDE plays only a moderate role in the (micro)aerobic respiration of $B$. cereus. However, these findings need to be confirmed by characterizing the cytochrome spectra and the oxygen uptake rates of mutant strains in order to determine whether the ResDE signal transduction pathway functions in the same way in B. cereus as in B. subtilis $(36,49)$.

Finally, our results indicated that the ResDE system governs glucose catabolism only when $B$. cereus was grown under lowORP anaerobiosis (i.e., under hydrogen atmosphere). This finding provides the first insight into the involvement of one $B$. subtilis ResDE ortholog within a redox regulatory network under anaerobic conditions.

By regulating catabolic flux, the ResDE system may also indirectly regulate the enterotoxin production of $B$. cereus F4430/73 (55). The data presented here also demonstrated that this two-component system (while dispensable) directly controlled the transcription of the PlcR-regulated genes $h b l$ and nhe. The ResDE system may thus provide a link between metabolism, redox conditions, and the regulation of enterotoxin expression in $B$. cereus. A key question is how ResDE controls the expression of PlcR-regulated enterotoxin genes? Examination of res $D E$ and res $E$ mutants revealed that it is the state of phosphorylation of ResD (modulated by ResE) rather than its presence or absence that may control the transcriptional activity of the protein. The control of enterotoxin gene transcription could thus have occurred at a step after the binding of ResD in the promoter region. While the interaction of $\mathrm{PlcR}$ with enterotoxin gene regulatory regions has been clearly established $(1,37)$, there is currently no experimental evidence that ResD interacts directly with these regulatory regions. However, analysis of the regulatory regions of $h b l$ and nhe suggested the presence of multiple potential ResD boxes (19, $35)$. The $\mathrm{Hbl}$ regulatory region may contain up to five binding sites for ResD. In contrast, it is likely that the nhe regulatory region may have only three binding sites for ResD (data not shown; www.prodoric.de). In addition, ResD belongs to the
OmpR-EnvZ class, which is part of the family of two-component regulatory proteins (23). Based on these observations, one could envisage a possible scenario for ResD-dependent regulation of $h b l$ and nhe in response to changes in redox conditions. The unphosphorylated form of ResD binds to the upstream regions of enterotoxin genes with various affinities. Increasing the phosphorylation of ResD in response to the decrease in oxygen availability and ORP leads to increased occupancy of adjacent ResD binding sites due to the stimulation of interactions, as in the case of $\operatorname{OmpR}(21,30)$. This increase in cooperative interactions, together with an additional regulator such as PlcR, could lead to high activation of enterotoxin genes under low-ORP anaerobic conditions. Differential activation of $h b l$ and nhe by low ORP (55) may thus be controlled by occupancy of ResD binding sites with various affinities. Finally, given that the absence of ResDE was not deleterious for enterotoxin transcription and that mRNA levels of enterotoxin genes did not match mRNA levels of $p l c R$ in the resDE mutant (Fig. 5), we can speculate that (an)other redox regulator(s) may supply the lack of ResDE by also acting independently from PlcR to activate enterotoxin gene expression. Candidate regulators include Fnr and/or YdiH.

In conclusion, our study provides the first data demonstrating the involvement of a two-component system, ResDE, in the metabolic adaptation of one pathogenic strain of the B. cereus group (39). The genes encoding this two-component system, and also their surrounding genes (res $A B C$ ), are highly conserved in the genomes of both pathogenic and nonpathogenic organisms of the B. cereus group. This could be revealing of the capacity of $B$. cereus group members to adapt to low ORP anaerobic growth conditions. The ResDE system responds to low-ORP anaerobic conditions by regulating fermentative genes and enterotoxin genes, accordingly. After ingestion as a food contaminant, B. cereus encountered in the host's small intestine an environment that is oxygen deprived $(17,45)$ and highly reducing (ORP $\sim-150 \mathrm{mV}$ [31]). The ResDE system may therefore facilitate $B$. cereus adaptation and ensure optimal virulence gene expression at the proper time during infection. Finally, although it is not clear whether the response regulator ResD directly interacts with the enterotoxin gene promoters, our study provides evidence that $\mathrm{PlcR}$ is not the sole activator of enterotoxin expression. Therefore, the transcription of enterotoxin gene could be controlled by at least two independent pathways, one involving ResDE and the other involving PlcR.

\section{ACKNOWLEDGMENT}

A.Z. received a fellowship from the Programme Inter-Gouvernemental Franco-Algerien.

\section{REFERENCES}

1. Agaisse, H., M. Gominet, O. A. Okstad, A. B. Kolsto, and D. Lereclus. 1999 $\mathrm{PlcR}$ is a pleiotropic regulator of extracellular virulence factor gene expression in Bacillus thuringiensis. Mol. Microbiol. 32:1043-1053.

2. Andersson, A., P. E. Granum, and U. Ronner. 1998. The adhesion of Bacillus cereus spores to epithelial cells might be an additional virulence mechanism. Int. J. Food Microbiol. 39:93-99.

3. Baruah, A., B. Lindsey, Y. Zhu, and M. M. Nakano. 2004. Mutational analysis of the signal-sensing domain of ResE histidine kinase from Bacillus subtilis. J. Bacteriol. 186:1694-1704.

4. Beecher, D. J., and J. D. Macmillan. 1991. Characterization of the components of hemolysin BL from Bacillus cereus. Infect. Immun. 59:1778-1784.

5. Beecher, D. J., and A. C. Wong. 1994. Identification and analysis of the 
antigens detected by two commercial Bacillus cereus diarrheal enterotoxin immunoassay kits. Appl. Environ. Microbiol. 60:4614-4616.

6. Beecher, D. J., J. L. Schoeni, and A. C. Wong. 1995. Enterotoxic activity of hemolysin BL from Bacillus cereus. Infect. Immun. 63:4423-4428.

7. Clark, D. P. 1989. The fermentation pathways of Escherichia coli. FEMS Microbiol. Rev. 5:223-234.

8. Clavel, T., F. Carlin, D. Lairon, C. Nguyen-The, and P. Schmitt. 2004. Survival of Bacillus cereus spores and vegetative cells in acid media simulating human stomach. J. Appl. Microbiol. 97:214-219.

9. Cruz Ramos, H., T. Hoffmann, M. Marino, H. Nedjari, E. Presecan-Siedel, O. Dreesen, P. Glaser, and D. Jahn. 2000. Fermentative metabolism of Bacillus subtilis: physiology and regulation of gene expression. J. Bacteriol 182:3072-3080.

10. Duport, C., S. Thomassin, G. Bourel, and P. Schmitt. 2004. Anaerobiosis and low specific growth rates enhance hemolysin BL production by Bacillus cereus F4430/73. Arch. Microbiol. 182:90-95.

11. Fagerlund, A., O. Ween, T. Lund, S. P. Hardy, and P. E. Granum. 2004 Genetic and functional analysis of the cytK family of genes in Bacillus cereus. Microbiology 150:2689-2697.

12. Finlay, B. B., and S. Falkow. 1997. Common themes in microbial pathogenicity revisited. Microbiol. Mol. Biol. Rev. 61:136-169.

13. Gohar, M., O. A. Okstad, N. Gilois, V. Sanchis, A. B. Kolsto, and D. Lereclus. 2002. Two-dimensional electrophoresis analysis of the extracellular proteome of Bacillus cereus reveals the importance of the PlcR regulon. Proteomics 2:784-791.

14. Gompertz, B. 1925. On the nature of the function expressive of the law of human mortality, and on a new mode of determining the value of life contingencies. Philos. Trans. R. Soc. 115:513-585.

15. Granum, P. E., K. O'Sullivan, and T. Lund. 1999. The sequence of the non-hemolytic enterotoxin operon from Bacillus cereus. FEMS Microbiol. Lett. 177:225-229.

16. Green, J., and M. S. Paget. 2004. Bacterial redox sensors. Nat. Rev. Microbiol. 2:954-966.

17. Guyton, A. C. 1977 . Basic human physiology, p. 408-423. In Normal function and mechanisms of diseases. W. B. Saunders Co., Philadelphia, Pa.

18. Hardy, S. P., T. Lund, and P. E. Granum. 2001. CytK toxin of Bacillus cereus forms pores in planar lipid bilayers and is cytotoxic to intestinal epithelia. FEMS Microbiol. Lett. 197:47-51.

19. Hartig, E., H. Geng, A. Hartmann, A. Hubacek, R. Munch, R. W. Ye, D. Jahn, and M. M. Nakano. 2004. Bacillus subtilis ResD induces expression of the potential regulatory genes $y c l J K$ upon oxygen limitation. J. Bacteriol. 186:6477-6484.

20. Hill, K. K., L. O. Ticknor, R. T. Okinaka, M. Asay, H. Blair, K. A. Bliss, M Laker, P. E. Pardington, A. P. Richardson, M. Tonks, D. J. Beecher, J. D. Kemp, A. B. Kolsto, A. C. Wong, P. Keim, and P. J. Jackson. 2004. Fluorescent amplified fragment length polymorphism analysis of Bacillus anthracis, Bacillus cereus, and Bacillus thuringiensis isolates. Appl. Environ. Microbiol. 70:1068-1080.

21. Huang, K. J., C. Y. Lan, and M. M. Igo. 1997. Phosphorylation stimulates the cooperative DNA-binding properties of the transcription factor OmpR. Proc. Natl. Acad. Sci. USA 94:2828-2832.

22. Ivanova, N., A. Sorokin, I. Anderson, N. Galleron, B. Candelon, V. Kapatral, A. Bhattacharyya, G. Reznik, N. Mikhailova, A. Lapidus, L. Chu, M. Mazur, E. Goltsman, N. Larsen, M. D'Souza, T. Walunas, Y. Grechkin, G. Pusch, R. Haselkorn, M. Fonstein, S. D. Ehrlich, R. Overbeek, and N. Kyrpides. 2003. Genome sequence of Bacillus cereus and comparative analysis with Bacillus anthracis. Nature 423:87-91.

23. Kojetin, D. J., R. J. Thompson, and J. Cavanagh. 2003. Sub-classification of response regulators using the surface characteristics of their receiver domains. FEBS Lett. 554:231-236.

24. Kotiranta, A., K. Lounatmaa, and M. Haapasalo. 2000. Epidemiology and pathogenesis of Bacillus cereus infections. Microbes Infect. 2:189-198.

25. Larsson, J. T., A. Rogstam, and C. von Wachenfeldt. 2005. Coordinated patterns of cytochrome $b d$ and lactate dehydrogenase expression in Bacillus subtilis. Microbiology 151:3323-3335.

26. Lindback, T., A. Fagerlund, M. S. Rodland, and P. E. Granum. 2004. Characterization of the Bacillus cereus Nhe enterotoxin. Microbiology 150:39593967.

27. Lund, T., and P. E. Granum. 1996. Characterisation of a non-hemolytic enterotoxin complex from Bacillus cereus isolated after a food-borne outbreak. FEMS Microbiol. Lett. 141:151-156.

28. Lund, T., M. L. De Buyser, and P. E. Granum. 2000. A new cytotoxin from Bacillus cereus that may cause necrotic enteritis. Mol. Microbiol. 38:254-261.

29. Mahillon, J., and D. Lereclus. 2000. Electroporation of Bacillus thuringiensis and Bacillus cereus, p. 242-252. In E. Teissie (ed.), Electrotransformation of bacteria. Verlag, Berlin, Germany.

30. Maris, A. E., D. Walthers, K. Mattison, N. Byers, and L. J. Kenney. 2005
The response regulator OmpR oligomerizes via beta-sheets to form headto-head dimers. J. Mol. Biol. 350:843-856.

31. Moriarty-Craige, S. E., and D. P. Jones. 2004. Extracellular thiols and thiol/ disulfide redox in metabolism. Annu. Rev. Nutr. 24:481-509.

32. Nakano, M. M., P. Zuber, P. Glaser, A. Danchin, and F. M. Hulett. 1996. Two-component regulatory proteins ResD-ResE are required for transcriptional activation of fnr upon oxygen limitation in Bacillus subtilis. J. Bacteriol. 178:3796-3802.

33. Nakano, M. M., Y. P. Dailly, P. Zuber, and D. P. Clark. 1997. Characterization of anaerobic fermentative growth of Bacillus subtilis: identification of fermentation end products and genes required for growth. J. Bacteriol. 179:6749-6755.

34. Nakano, M. M., and P. Zuber. 1998. Anaerobic growth of a "strict aerobe" (Bacillus subtilis). Annu. Rev. Microbiol. 152:165-190.

35. Nakano, M. M., Y. Zhu, M. Lacelle, X. Zhang, and F. M. Hulett. 2000 Interaction of ResD with regulatory regions of anaerobically induced genes in Bacillus subtilis. Mol. Microbiol. 37:1198-1207.

36. Nakano, M. M., and Y. Zhu. 2001. Involvement of ResE phosphatase activity in down-regulation of ResD-controlled genes in Bacillus subtilis during aerobic growth. J. Bacteriol. 179:1938-1944.

37. Okstad, O. A., M. Gominet, B. Purnelle, M. Rose, D. Lereclus, and A. B. Kolsto. 1999. Sequence analysis of three Bacillus cereus loci carrying PIcRregulated genes encoding degradative enzymes and enterotoxin. Microbiology 145:3129-3138.

38. Pfaff, M. W. 2001. A new mathematical model for relative quantification in real-time RT-PCR. Nucleic Acids Res. 29:2002-2007.

39. Rasko, D. A., M. R. Altherr, C. S. Han, and J. Ravel. 2005. Genomics of Bacillus cereus group of organisms. FEMS Microbiol. Rev. 29:303-329.

40. Reents, H., R. Munch, T. Dammeyer, D. Jahn, and E. Hartig. 2006. The Fnr regulon of Bacillus subtilis. J. Bacteriol. 188:1103-1112.

41. Rosenfeld, E., C. Duport, A. Zigha, and P. Schmitt. 2005. Characterisation of aerobic and anaerobic vegetative growth of the food-borne pathogen Bacillus cereus. Can. J. Microbiol. 51:149-158.

42. Ryan, P. A., J. D. Macmillan, and B. A. Zilinskas. 1997. Molecular cloning and characterization of the genes encoding the L1 and L2 components of hemolysin BL from Bacillus cereus. J. Bacteriol. 179:2551-2556.

43. Sanchez, A. M., G. N. Bennett, and K. Y. San. 2005. Effect of different levels of NADH availability on metabolic fluxes of Escherichia coli chemostat cultures in defined medium. J. Biotechnol. 117:395-405.

44. Schoeni, J. L., and A. C. Wong. 2005. Bacillus cereus food poisoning and its toxins. J. Food Prot. 68:636-648.

45. Skinner, F. A., and J. G. Carr. 1975. The normal microbial flora of man. Academic Press, London, England.

46. Slamti, L., and D. Lereclus. 2002. A cell-cell signaling peptide activates the $\mathrm{PlcR}$ virulence regulon in bacteria of the Bacillus cereus group. EMBO J. 21:4550-4559

47. Spira, W. M., and J. M. Goepfert. 1975. Biological characteristics of an enterotoxin produced by Bacillus cereus. Can. J. Microbiol. 21:1236-1246.

48. Stock, J., and S. Da Re. 2000. Signal transduction: response regulators on and off. Curr. Biol. 10:420-424.

49. Sun, G., E. Sharkova, R. Chesnut, S. Birkey, M. F. Duggan, A. Sorokin, P. Pujic, S. D. Ehrlich, and F. M. Hulett. 1996. Regulators of aerobic and anaerobic respiration in Bacillus subtilis. J. Bacteriol. 178:1374-1385.

50. Taylor, B. L., and I. B. Zhulin. 1999. PAS domains: internal sensors of oxygen, redox potential, and light. Microbiol. Mol. Biol. Rev. 63:479-506.

51. Vagner, V., E. Dervyn, and S. D. Ehrlich. 1998. A vector for systematic gene inactivation in Bacillus subtilis. Microbiology 144:3097-3104.

52. Wilcks, A., B. M. Hansen, N. B. Hendriksen, and T. R. Licht. 2006. Fate and effect of ingested Bacillus cereus spores and vegetative cells in the intestinal tract of human-flora-associated rats. FEMS Immunol. Med. Microbiol. 46: $70-77$.

53. Yarwood, J. M., J. K. McCormick, and P. M. Schlievert. 2001. Identification of a novel two-component regulatory system that acts in global regulation of virulence factors of Staphylococcus aureus. J. Bacteriol. 183:1113-1123.

54. Ye, R. W., W. Tao, L. Bedzyk, T. Young, M. Chen, and L. Li. 2000. Global gene expression profiles of Bacillus subtilis grown under anaerobic conditions. J. Bacteriol. 182:4458-4465.

55. Zigha, A., E. Rosenfeld, P. Schmitt, and C. Duport. 2006. Anaerobic cells of Bacillus cereus $\mathrm{F} 4430 / 73$ respond to low oxidoreduction potential by metabolic readjustments and activation of enterotoxin expression. Arch. Microbiol. 185:222-233.

56. Zwietering, M., I. Jongenburger, F. Rombouts, and K. van't Riet. 1990. Modeling of the bacterial growth curve. Appl. Environ. Microbiol. 56:18751881.

57. Zwietering, M. H., F. M. Rombouts, and K. van't Riet. 1992. Comparison of definitions of the lag phase and the exponential phase in bacterial growth. J. Appl. Bacteriol. 72:139-145. 